\title{
Tratamento ortopédico em paciente com deficiência de maxila: relato de caso
}

\author{
Orthopedic treatment in a patient with maxillary deficiency: a case report \\ Tratamiento ortopédico en un paciente con deficiencia maxilar: reporte de un caso
}

Recebido: 10/12/2021 | Revisado: 14/12/2021 | Aceito: 15/12/2021 | Publicado: 22/12/2021

\author{
Geanne da Silva Ferreira \\ ORCID: https://orcid.org/0000-0001-5017-7179 \\ Centro Universitário Fametro, Brasil \\ E-mail: geanneferreira1@gmail.com \\ Lorena Cabral dos Santos \\ ORCID: https://orcid.org/0000-0002-0751-1597 \\ Centro Universitário Fametro, Brasil \\ E-mail: lorenacabraldossantos@gmail.com \\ Joyce de Figueiredo Meira \\ ORCID: https://orcid.org/0000-0001-5156-236X \\ Centro Universitário Fametro, Brasil \\ E-mail: joycefmeira@fametro.edu.br \\ Roberto Luiz de Menezes Martinho \\ ORCID: https://orcid.org/0000-0002-0854-5190 \\ Centro Universitário Fametro, Brasil \\ E-mail: roberto.martinho@fametro.edu.br \\ Nayhane Cristine da Silva de Oliveira \\ ORCID: https://orcid.org/0000-0003-2056-5853 \\ Centro Universitário Fametro, Brasil \\ E-mail: nayhane.oliveira@ fametro.edu.br \\ Bruna Ramos Meireles dos Santos \\ ORCID: https://orcid.org/0000-0002-3796-4925 \\ Universidade Estadual do Amazonas, Brasil \\ E-mail: bruna.maisonoral@gmail.com \\ Gabriela de Figueiredo Meira \\ ORCID: https://orcid.org/0000-0002-8285-8769 \\ Universidades Federal de Santa Maria, Brasil \\ E-mail: gabrielameira1@ hotmail.com \\ Jéssica Tuane Maia Rêgo \\ ORCID: https://orcid.org/0000-0001-9396-4201 \\ Cuidando do Sorriso de Manaus Clinica Odontológica, Brasil \\ E-mail: tuanemaia@gmail.com
}

\begin{abstract}
Resumo
Objetivo: o objetivo desse artigo é descrever um caso clínico de tratamento ortodôntico e ortopédico de uma criança de nove anos, Classe III de Angle com uso de máscara facial. Metodologia: Partindo da permissão da paciente por meio do Termo de Consentimento Livre e Esclarecido em partilhar sua imagem para devido fim, o presente estudo trata de um relato de caso clínico de cunho analítico descritivo (Pereira et al., 2018). Relato de Caso: A paciente I. A. C 9 anos, gênero feminino, branca, compareceu a clínica odontológica do Centro Universitário Fametro (CEUNIFAMETRO) acompanhada pela mãe, queixando-se da "vergonha de sorrir". Após a assinatura do Termo de Consentimento Livre e Esclarecido (TCLE), foi realizada a anamnese, no qual a responsável relatou bom estado de saúde da criança e hábito de respiração bucal. Considerações Finais: Diante do exposto, pode-se afirmar que os resultados do tratamento de discrepância esquelética por deficiência maxilar não foram alcançados. No presente relato de caso, a paciente não foi colaborativa, o que culminou em troca de disjuntor devido a criança ter quebrado o aparelho por duas vezes.
\end{abstract}

Palavras-chave: Mordida; Classe III; Má oclusão; Criança.

\begin{abstract}
Objective: The aim of this article is to describe a clinical case of orthodontic and orthopedic treatment of a nine-yearold child, Angle Class III, using a face mask. Methodology: Based on the patient's permission through the Free and Informed Consent Form to share her image for the proper purpose, this study is a clinical case report of descriptive analytical nature (Pereira et al., 2018). Case Report: Patient I. A. C, 9 years old, female, white, attended the dental clinic of Centro Universitário Fametro (CEUNI-FAMETRO) accompanied by her mother, complaining about the "shame of smiling". After signing the Informed Consent Form (FICF), an anamnesis was carried out, in which the guardian reported the child's good health and mouth breathing habits. Final Considerations: Given the above, it can be stated that the results of the treatment of skeletal discrepancy due to maxillary deficiency were not achieved. In the
\end{abstract}


present case report, the patient was uncooperative, which culminated in changing the circuit breaker due to the child having broken the device twice.

Keywords: Bite; Class III; Malocclusion; Kid.

\section{Resumen}

Objetivo: El objetivo de este artículo es describir un caso clínico de tratamiento ortodóncico y ortopédico de un niño de nueve años, Angle Clase III, utilizando una mascarilla facial. Metodología: Con base en el permiso de la paciente a través del Formulario de Consentimiento Libre e Informado para compartir su imagen con el propósito adecuado, este estudio es un reporte de caso clínico de naturaleza analítica descriptiva (Pereira et al., 2018). Caso clínico: Paciente I. A. C, 9 años, mujer, blanca, acudió a la clínica dental del Centro Universitário Fametro (CEUNI-FAMETRO) acompañada de su madre, quejándose de la "vergüenza de sonreír". Luego de firmar el Formulario de Consentimiento Informado (FICF), se realizó una anamnesis, en la cual el tutor reportó el buen estado de salud y hábitos de respiración bucal del menor. Consideraciones finales: Dado lo anterior, se puede afirmar que no se alcanzaron los resultados del tratamiento de la discrepancia esquelética por deficiencia maxilar. En el presente caso clínico, el paciente no se mostró dispuesto a cooperar, lo que culminó con el cambio del disyuntor debido a que el niño había roto el dispositivo dos veces.

Palabras clave: Mordida; Clase III; Maloclusión; Niño

\section{Introdução}

O sistema estomatognático compreende a mandíbula e maxila, dentes e músculos e juntos permitem a oclusão dos elementos dentários. Uma oclusão normalmente se define pela harmonia dessas estruturas (Yamaguto \& Vasconcelos, 2009).

Segundo Silva Filho et al., (1989), durante o desenvolvimento da oclusão, o homem atravessa três estágios: dentaduras decídua, mista e permanente. A má-oclusão ou maloclusão é resultante da alteração no desenvolvimento e crescimento craniofacial que afeta a posição dos dentes na arcada, afetando diretamente na qualidade de vida, ocasionando em baixa autoestima desde a infância. Existem inúmeras etiologias para a má-oclusão, como por exemplo: fatores hereditários, hábitos bucais deletérios, congênitos, e adquiridos, todos estes podem contribuir para que esta alteração se instale ou se agrave (Leôncio et al., 2015).

A mordida cruzada anterior é a maloclusão em que pode ser resultante do posicionamento lingual dos elementos anteriores superiores (incisivos, caninos e pré-molares) em relação aos elementos anteriores inferiores (TSE, 2001). De acordo com estudos realizados por Moyers (1991), a mordida cruzada anterior pode ser dividida segundo sua origem, em três tipos: dentária ou dental, funcional e esquelética.

A mordida cruzada anterior dental ocorre devido a uma alteração na inclinação de um ou mais elementos, podendo ser caracterizada pela presença dos dentes superiores posicionados por palatina com vestíbuloversão dos elementos antagonistas, estando a relação maxilomandibular correta. Além disso, os pacientes acometidos por essa alteração apresentam relação molar de classe I (Bayrak \& Tun, 2008).

A mordida cruzada anterior funcional, também chamada de pseudo classe III, é aquela onde ocorre o comprometimento das bases ósseas apicais, ocasionada pela interferência dental instalada de forma precoce, onde acontece a força na mandíbula para mover-se, a fim de obter a máxima intercuspidação (MIH), sendo que em relação cêntrica (RC), os incisivos tanto superiores quanto inferiores apresentam topo-a-topo, com os molares separados, mas em relação molar de classe I (Bayrak \& Tun, 2008).

As más oclusões de Classe III são apresentadas através do posicionamento mais anterior da mandíbula em relação à maxila. No entanto, a discrepância pode ser causada pela deficiência anterior da maxila, prognatismo mandibular excessivo ou a combinação de ambas as alterações (Boeck et al., 2005). Os elementos dentários apresentam-se com inclinações compensadas, mas de maneira inversa, pois os incisivos superiores podem se encontrar vestibularizados e os incisivos inferiores lingualizados. 
O desenvolvimento de classe III afeta a aparência e a harmonia dentofacial, podendo acarretar em problemas psicológicos para as crianças, onde elas desenvolvem atitudes negativas de autodepreciação e problemas psicológicos envolvendo a autoestima, mesmo que submetidos a cirurgias corretivas (Stricker G, et al., 1979; Flannary et al., 1990 apud Primo, et al., 2010).

A mordida cruzada esquelética apresenta-se através da assimetria do crescimento ósseo maxilomandibular. Ainda com relação a este tipo de alteração, ocorre a compensação dos incisivos, com perfil nitidamente côncavo. Os incisivos superiores estão inclinados para frente e os inferiores estão inclinados para trás (Rosa et al., 2012; Seehra et al., 2012).

Como forma de tratamento para as deformidades craniofaciais interligado a deficiências no maxilar, a opção mais indicada é o uso do aparelho facial extrabucal, mais conhecido como máscara facial, no qual proporciona uma força anterior constante da maxila (Suassuna et al., 2018). O uso da máscara facial é indicado como método não cirúrgico para tratamento de casos onde há a maloclusão classe III em crianças em crescimento (Primo et al., 2010).

O uso da máscara facial desencadeia em movimentos anteroinferiores da parte posterior da maxila e dos dentes superiores, uma rotação horária da mandíbula e uma inclinação para lingual dos incisivos inferiores (Goh \& Kaan, 1992). Ocorre também um movimento do nariz para frente, diminuindo a concavidade do perfil, resultando em um perfil mais simétrico e harmonioso (Oltramari, 2005).

Portanto, o objetivo desse artigo é descrever um caso clínico de tratamento ortodôntico e ortopédico de uma criança de nove anos, Classe III de Angle com uso de máscara facial.

\section{Metodologia}

Partindo da permissão da paciente por meio do Termo de Consentimento Livre e Esclarecido em partilhar sua imagem para devido fim, o presente estudo trata de um relato de caso clínico de cunho analítico descritivo (Pereira et al., 2018) sobre fechamento de diastemas através da técnica direta de resina composta, realizado na clínica odontológica do CEUNI Fametro, na disciplina de estágio supervisionado em Clínica Integrada III, do curso de graduação em odontologia do Centro Universitário Fametro.

\section{Resultados e Discussão}

A paciente I. A. C 9 anos, gênero feminino, branca, compareceu a clínica odontológica do Centro Universitário Fametro (CEUNI- FAMETRO) acompanhada pela mãe, queixando-se da "vergonha de sorrir". Após a assinatura do Termo de Consentimento Livre e Esclarecido (TCLE), foi realizada a anamnese, no qual a responsável relatou bom estado de saúde da criança e hábito de respiração bucal (Figura 1). 
Figura 1 - Fotografias faciais: frontal, frontal sorrindo e perfil direito.

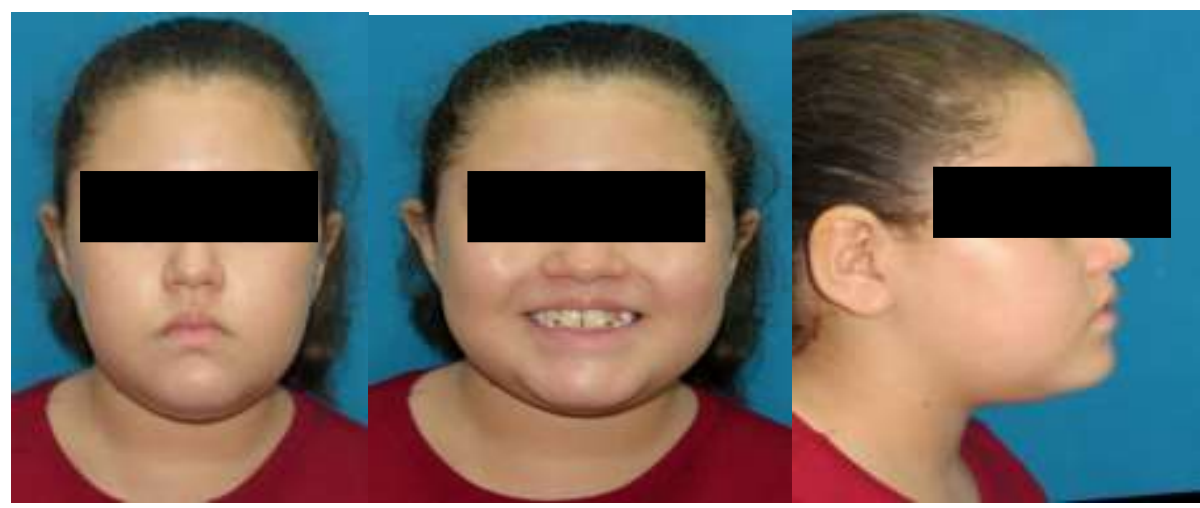

Fonte: CIMO

Ao exame extraoral, a paciente não apresentava selamento labial passivo assimetria do lado direito da face, retrusão maxilar e protusão mandibular, sulco nasogeniano e a depressão orbitária pouco expressivos, sulco mento-labial plano. $\mathrm{Na}$ análise facial de perfil, notou-se que a paciente apresenta convexidade facial reduzida, ângulo naso-labial, projeção zigomática deficiente e sulco mento labial aberto.

No exame clinico intraoral, observou-se que a paciente encontrava-se no período de dentadura mista, com a presença dos elementos dentários decíduos 55, 54, 63, 64, 65, 75, 74, 73, 83, 84 e elementos permanentes 16, 12, 11, 21, 22, 26, 36, 32,41, 42 e 46, possuía lesão de cárie no elemento 63 e 65, mordida cruzada anterior do lado esquerdo e vestibuloversão no elemento 13.

Figura 2 - Fotografias intraorais: lateral direita (A), frontal (B), lateral esquerda (C), oclusal superior (D) e oclusal inferior (E).

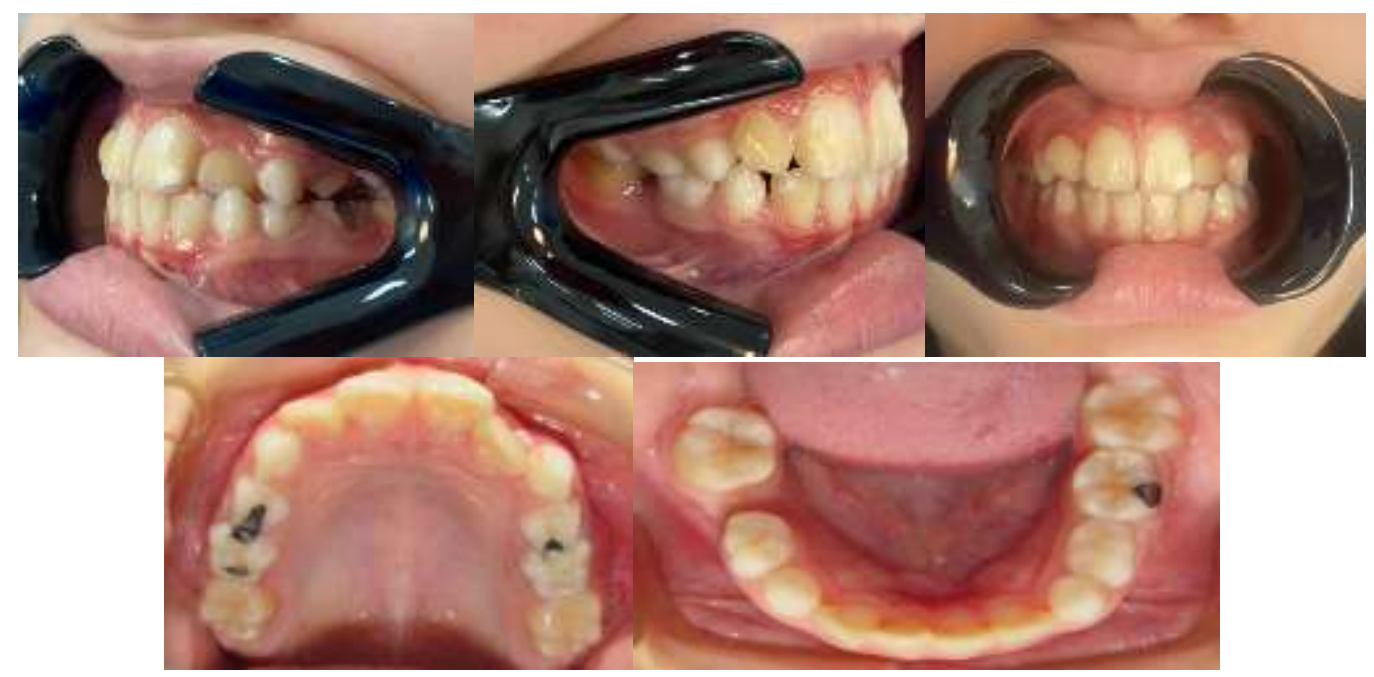

Fonte: Fametro.

Foi observada a ausência do elemento 85, já com perda de espaço, o qual a mãe relatou que esse dente foi extraído porque estava com lesão de cárie extensa. Foi constatada a relação dos molares e caninos classe II de Angle lado direito e equerdo classe III.

$\mathrm{Na}$ análise radiográfica panorâmica (Figura 3), verificou-se a presença de todos os germes permanentes, exceto dos elementos 18,28, 38 e 48. Observou-se os elementos 13 e 23 no estágio 8 de Nolla, inclinação para mesial e mesialização do elemento 46. 
Figura 3 - A) Radiografia Panorâmica inicial da paciente; B) Telerradiografia da paciente
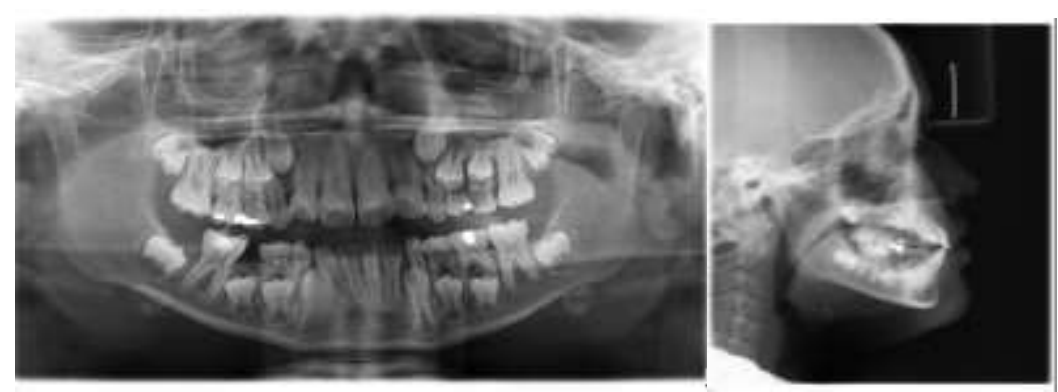

Fonte: CIMO

De acordo com os achados clínicos e radiográficos, o diagnóstico foi discrepância esquelética por deficiência maxilar. Portanto, o plano de tratamento proposto foi expansão rápida da maxila associada a tração reversa com uso do disjuntor Macnnara e máscara facial de Petit Morelli®.

Inicialmente, foi realizada adequação do meio bucal com profilaxia e orientações quanto a escovação e o uso do fio dental e restaurações com resina composta Opallis® cor EA3,5.

Para o tratamento ortopédico, foi realizada a moldagem utilizando Alginato Jeltrate® e confecção do modelo com gesso tipo IV Duramix ${ }^{\circledR}$, o qual foi enviado para o protético para confecção do disjuntor McNamara com gancho e torno expansor de $13 \mathrm{~mm}$. Para instalação do aparelho foram feitos os ajustes necessários e a cimentação com cimento de ionômero de vidro. Nessa consulta, foram feitas as orientações de higiene bucal e explicado o protocolo de ativação que consistiu em $2 / 4$ de voltas duas vezes por dia, manhã e noite após a escovação por 7 dias (Figura 4 e 5).

Figura 4 - A) Foto com o aparelho de Haas instalado vista pelo palato; B) extraoral (vista vestibular).

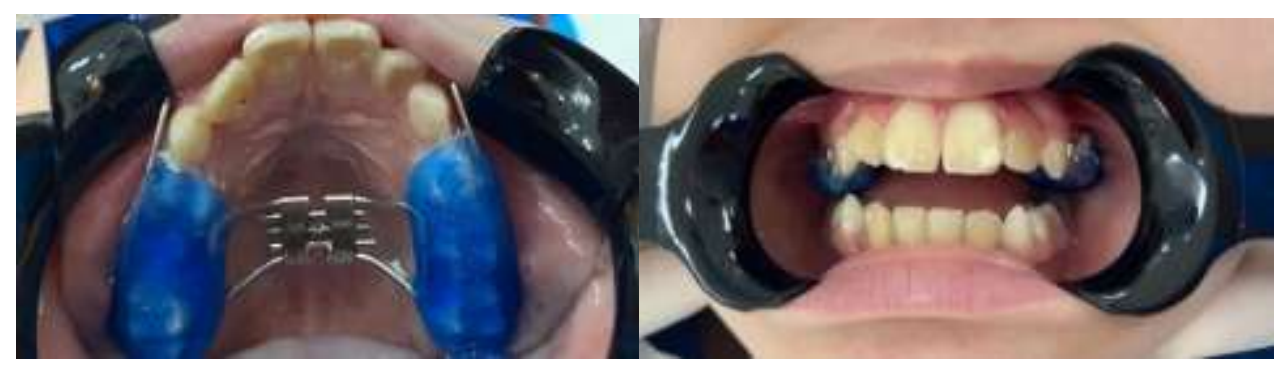

Fonte: Autores. 
Figura 5 - A) Máscara facial de Petit frontal; B) Máscara facial de Petit frontal sorrindo; C) Máscara facial de Petit perfil esquerdo; D) Figura 9- Máscara facial de Petit perfil direito.

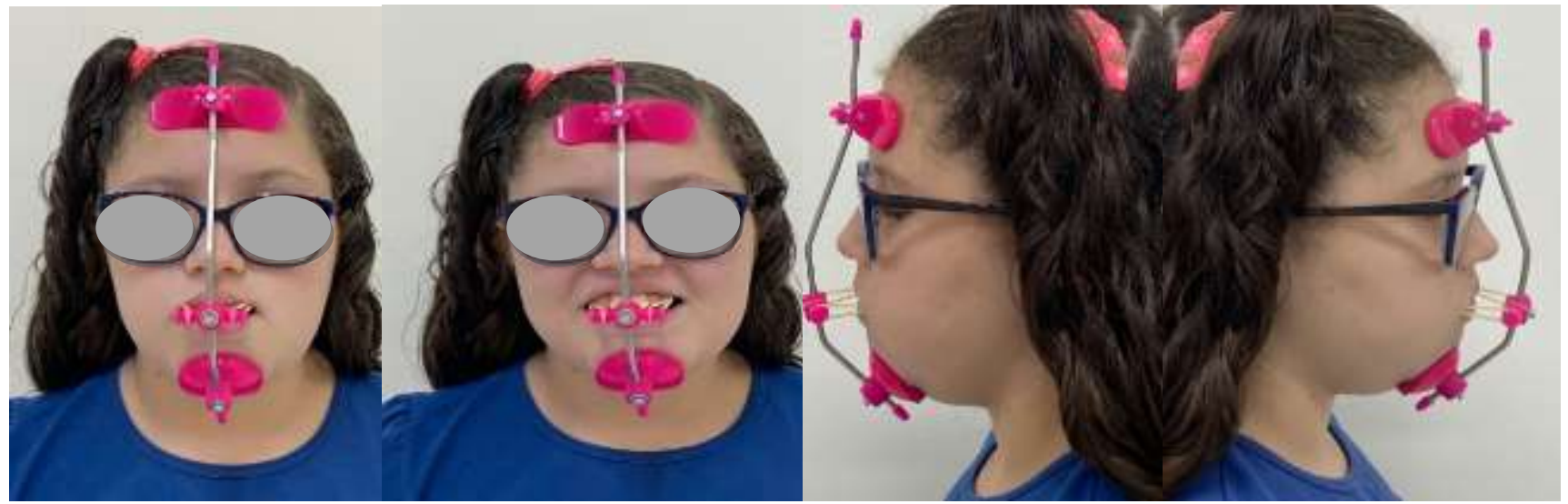

Fonte: Autores.

Após o 7 dias a máscara de Petit foi instalada, centralizada com a linha média da paciente de forma que o apoio para os elásticos ficasse entre os lábios. Foram utilizados elásticos $1 / 2$ pesado de forma que fosse empregada 400 gramas de força em ambos os lados, mensurada por meio de um tensiômetro. A responsável foi orientada a realizar a troca dos elásticos a cada 4 dias e a máscara por 16 horas, sendo removida apenas nos horários das aulas e alimentação.

No segundo mês, tratamento foi interrompido por 15 dias devido a quebra do aparelho por falta de colaboração da paciente. Dessa forma, uma nova cimentação do McNamara foi realizada.

Devido a quebra constante do disjuntor, foi realizada a substituição pelo expansor de Hyrax, onde novamente foi realizada a expansão rápida da maxila com protocolo de $2 / 4$ de voltas duas vezes por dia durante 7 dias e posteriormente a instação da máscara de Petit (Figura 6).

Figura 6 - A) Aparelho hirax instalado; B) Resultado parcial intrabucal (visão pelo palato); C) Ganchos vestibulares: Visão pelo lado esquerdo; D) Ganchos vestibulares: Visão pelo lado direito.

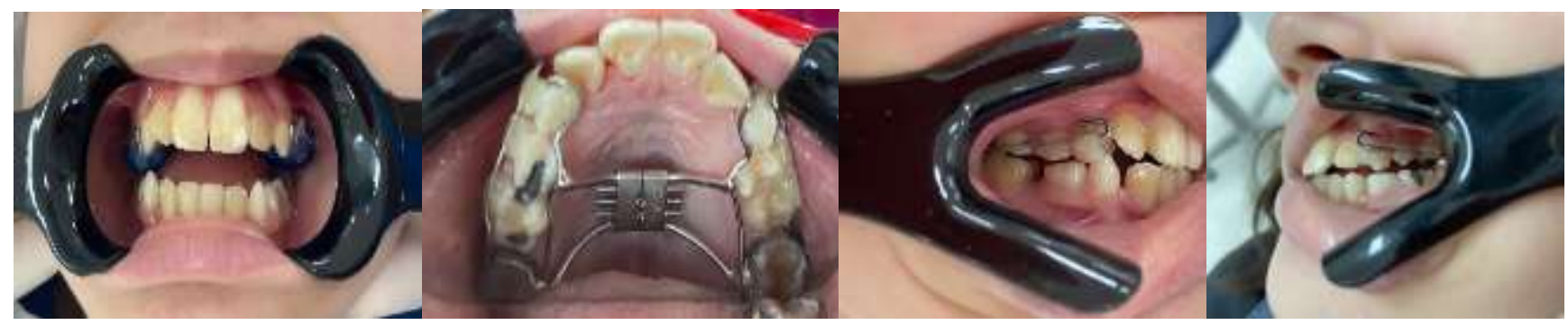

Fonte: Autores.

O tratamento prosseguiu por 7 meses mesmo com a quebra do aparelho em momentos distintos. No momento da reavaliação, verificou-se presença de inflamação gengival e necessidade de extração do elemento 83 (figura 7 e 8 ). 
Figura 7 - Comparação do perfil: A) Antes do tratamento; B) Após 7 meses de tratamento.

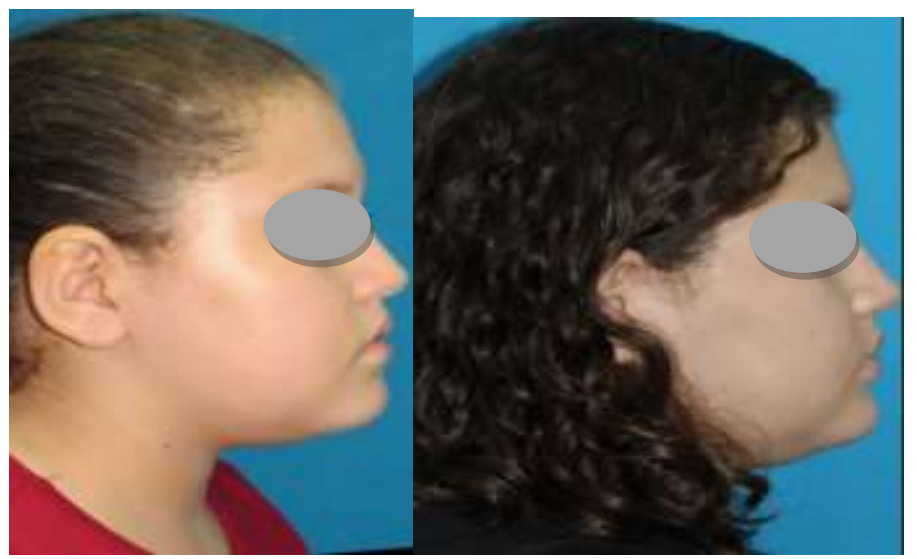

Fonte: Autores.

Figura 8- A) Antes do tratamento; B) Após 7 meses de tratamento (frontal sorrindo).

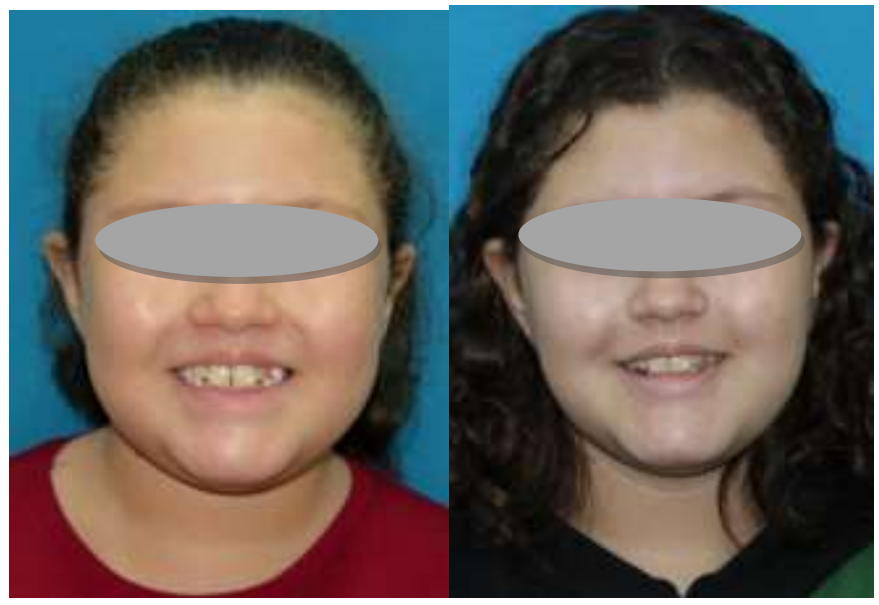

Fonte: Autores.

Portanto, o tratamento foi realizado o reforço quanto aos cuidados da higiene bucal tanto para criança quanto para a responsável. Novos exames de imagem foram solicitados a fim de acompanhamento do tratamento.

\section{Discussão}

De acordo com Miguel et al., (2008) existem diversas condutas para que se possa obter sucesso no tratamento de más oclusões classe III de Angle, dentre elas: idade esquelética e dentária do paciente. O tratamento da Classe III mais assertivo ocorre quando há a intervenção no início da dentadura mista, antes do crescimento puberal, podendo ser ainda indicada a intervenção no final da dentição decídua. Corroborando com esses princípios, Arruda et al., (2017) relataram em suas pesquisas que além das diversas condutas e opções de tratamento dessas más oclusões, a alternativa aceitável e primordial é através de ortodontia associada a Ortopedia funcional, visando sempre uma correção satisfatória e precoce da maloclusão.

Aos oitos anos de idade, no período intertransitório da dentição mista, tem-se a redução dos efeitos ortopédicos e aumento dos efeitos dentários através da vestibularização dos incisivos, fazendo com que se tenha melhora no perfil (Baccetti et al., 2007). No entanto, Woon et al., (2015) relataram em seus estudos que na fase da puberdade é a opção mais relevante atualmente, afim de melhorar a qualidade de vida e diminuir a realização de futuras intervenções cirúrgicas. Para o presente relato de caso, a paciente ainda não havia atingido a puberdade, conforme relatado pela sua genitora. Importante ressaltar que 
os efeitos negativos se sobressaem nessa fase, tendo em vista que pode afetar diretamente na auto-estima, nos estudos (medo de bullying) e estes se perdurarem até a fase adulta caso não se consiga um resultado satisfatório.

O diagnóstico precoce da Classe III esquelética poderá evitar a submissão do paciente a tratamentos mais invasivos, como cirurgia ortognática. Sua abordagem terapêutica através da utilização de aparelhos de tração reversa, como a máscara facial, propiciará sua correção sua correção através da readequação do crescimento facial. Dentre os diversos modelos disponíveis no mercado, a máscara de Petit, tem maior aceitação pelos pacientes, além de proporcionar sucesso no tratamento proposto (Oliveira \& Dobranszki, 2019). Além dessa opção, encontra-se ainda na literatura, diversos outros planos de tratamentos ortopédicos e ortodônticos para a correção deste tipo de mal oclusão. De acordo com cada caso específico, pode-se recorrer a um tratamento incluindo aparelhos intra e extra orais, tais como: twin-block invertido, aparelho de Frankel, máscara facial de Petit, mentoneira, bionator, retrator mandibular removível (mola progênica), elásticos de Classe III e miniplacas para ancoragem esquelética (Rodrigues et al., 2007).

O protocolo recomendado é o uso apenas do disjuntor com ativação por 7 dias para, imediatamente após o término das ativações, instalar a máscara de protração maxilar. O aparelho do tipo dento-muco-suportado de Haas teve a preferência da maioria dos autores (Garib et al., 2005: Suassuna et al., 2018). Corroborando com a literatura, o disjuntor escolhido foi o Haas, por ter ancoragem e sua eficácia no tratamento ortopédico ser consideravelmente maior se comparada a outro tratamento convencional. No entanto, Belardo (2018) relatou em seu estudo de caso que a paciente obteve sucesso com a terapia de expansão rápida da maxila realizada no qual utilizou-se o aparelho Hyrax, associado à terapia de tração reversa da maxila realizado com a máscara facial de Petit.

\section{Considerações Finais}

Diante do exposto, pode-se afirmar que os resultados do tratamento de discrepância esquelética por deficiência maxilar não foram alcançados. No presente relato de caso, a paciente não foi colaborativa, o que culminou em troca de disjuntor devido a criança ter quebrado o aparelho por duas vezes. Por conseguinte, além de a família ter papel fundamental no estímulo e sucesso do tratamento, pode-se afirmar que estas alterações geram efeitos negativos em todas as fases de vida do paciente, seja ela na infância, juventude ou vida adulta.

\section{Referências}

Arruda, R. T., Cruz, C. M., Crepaldi, M. V., Santana, A. P., \& Junior, C. H. G. (2017). Tratamento precoce da classe II. Rev Faipe. 7(1), 25-35.

Baccetti, T., Franchi, L., \& Mcnamara, J. A. (2007). Growth in the untreated Class III subject. InSeminars in Orthodontics. Elsevier. 13 (3),130-142.

Bayrak, S., \&Tun, E. S. (2008). Treatment of anterior dental crossbite using bonded resin-composite slopers: case reports. Eur J Dent. 2(2), $3003-306$.

Boeck, E. M., et al. (2005). Tratamento ortodôntico-cirúrgico da má oclusão de Classe III. R Clin Ortodon Dental Press, Maringá. 4(2), 46-52.

Garib, D. G., Henriques, J. F., Janson, G., Freitas, M. R., \& Coelho, R. A. (2005). Rapid maxillary expansion-- tooth tissue-borne versus tooth-borne expanders: a computed tomography evaluation of dentoskeletal effects. The Angle orthodontist, 75(4), 548-57.

Goh, G., \& Kaan, S. K. (1992). Dentofacial orthopedic correction of maxillary retrusion with the protraction facemask literature review. Aust Orthod J. 12(3), $143-50$.

Leôncio, L. L., Furtado, K. K., Chacon, L. D., Nóbrega, C. B., Costa, L. E., \& Queiroz, F. D. (2015). Prevalência de má-oclusão em crianças de cinco anos de idade do município de Patos, PB. Arq Odontol, 51(1), 25-31.

Miguel, J. A., Canavarro, C., Ferreira, J. D., Brunharo, I. H., \& Almeida, M. A. (2000). Diagnóstico de má oclusão de Classe III por alunos de graduação. Revista Dental Press de Ortodontia e Ortopedia Facial, 13(6), 118-27.

Moyers, R. E. (1991). Ortodontia. Do original: Handbook of Orthodontics, 1988. Revisão Técnica por Aloysio Cariello. (4a ed.), Guanabara Koogan; 483p.

Oliveira, J. F., \& Dobranszki, A. (2019). Tração ortopédica com máscara facial de Petit e expansor maxilar com splint acrílico: Relato de caso. $R$ Odontol Planal Cent, Jul-Dez; 9(2), 3-11. 
Research, Society and Development, v. 10, n. 17, e127101724607, 2021

(CC BY 4.0) | ISSN 2525-3409 | DOI: http://dx.doi.org/10.33448/rsd-v10i17.24607

Oltramari, P.V., Garib, D. G., Conti, A. C., Henriques, J. F., \& Freitas, M. R. (2005). Tratamento ortopédico da Classe III em padrões faciais distintos. Revista Dental Press de Ortodontia e Ortopedia Facial . 10(5), 72-82.

Primo, B. T., Eidt, S. V., Gregianin, J. A., Primo, N. A., Junior, I. M. (2010). Terapia da tração reversa maxilar com máscara facial de Petit - relato de caso. RFO. 15(2), 171-6.

Rodrigues, L. R., Baddredine, F. R., Junior, M. C., França, N. M. (2007). Protração maxilar associada à disjunção maxilar ortopédica. Rev. Clín. Ortodon. Dental Press, Maringá. 6(3), 48-56.

Rosa, M., et al. (2012). Spontaneous correction of anterior crossbite by RPE acnhored on deciduous teeth in the early mixed dentition. European Journal of Paediatric dentistry. 13(3), 176-80.

Seehra, J., Fleming, P. S., Mandall, N., Dibiase, A. T. (2011). A comparison of two different techniques for early correction of Class III malocclusion. The Angle Orthodontist, 82(1), 96-101.

Silva Filho, O. G., Freitas, S. F., Cavassan, A. O. (1989). Prevalência de oclusão normal e má oclusão na dentadura mista em escolares da cidade de Bauru (São Paulo). Rev Assoc Paul Cir Dent. 43(6), 287-90.

Suassuna, K. M, Santos, D. C., Negrete, D., Flaiban, E., Santos, R. L., Bortolin, R. (2019). Expansão e disjunção palatina em pacientes classe III com uso de máscara facial. Revista de Odontologia da Universidade Cidade de São Paulo . 30(3), 290.

TSE, C. S. (1997). Correction of single-tooth anterior crossbite. J Clin Orthod. 31(3):188.

Woon, S. C., \& Thiruvenkatachari, B. (2017). Early orthodontic treatment for Class III malocclusion: A systematic review and meta-analysis. American Journal of Orthodontics and Dentofacial Orthopedics, 151, 28-52.

Yamaguto, O. T., Vasconcelos, M. H. (2005). Determinação das medidas dentárias mésio-distais em indivíduos brasileiros leucodermas com oclusão normal. Revista Dental Press de Ortodontia e Ortopedia Facial . 10(5), 99-107. 